\title{
Caracterização do Igarapé Chico Reis, Rorainópolis - RR e restauração de matas ciliares na Amazônia: um referencial teórico
}

Characterization of Igarapé Chico Reis, Rorainópolis - RR and restoration of river forests in the

Amazon: a theoretical framework

Caracterización de Igarapé Chico Reis, Rorainópolis - RR y restauración de bosques río en la

Amazonía: un marco teórico

Recebido: 04/11/2021 | Revisado: 15/11/2021 | Aceito: 17/11/2021 | Publicado: 27/11/2021

\author{
Danielle Maria Dias dos Santos \\ ORCID: https://orcid.org/0000-0002-0107-8833 \\ Universidade Estadual de Roraima, Brasil \\ E-mail: danielle.santos@alunos.uerr.edu.br \\ Macksuel Fernandes da Silva \\ ORCID: https://orcid.org/0000-0003-2225-8478 \\ Universidade Federal de Goiás, Brasil \\ E-mail: macksuelfernandes@hotmail.com \\ Pedro Augusto Fonseca Lima \\ ORCID: https://orcid.org/0000-0001-5360-0104 \\ Universidade Estadual de Roraima, Brasil \\ E-mail: pedrofons@gmail.com
}

\begin{abstract}
Resumo
A água desenvolve papel fundamental na manutenção da vida na Terra. Dentre as Bacias Hidrográficas presentes no Brasil, destaca-se a Bacia Hidrográfica Amazônica. Para manutenção da integridade dessa bacia, bem como da disponibilidade e qualidade de água, é necessário a conservação das faixas de vegetação nativa que margeiam seus corpos d'água, denominadas de matas ciliares. Nessa região a ocupação urbana ocorreu nas adjacências dos corpos hídricos, de forma irregular e desordenada. Essa situação aumenta a chance de inundações e desbarrancamentos nas margens dos rios ocasionadas pela retirada das matas ciliares. Vários municípios que estão localizados na Bacia Hidrográfica Amazônica se encontram nessas condições, como por exemplo, no município de Rorainópolis-RR. Alguns trechos do Igarapé Chico Reis, principal corpo hídrico que corta o município de Rorainópolis, se encontram em processo de degradação tornando-se essencial sua restauração. Várias técnicas de restauração podem e devem ser aplicadas em matas ciliares degradadas, bem como o uso de indicadores para avaliar o sucesso da restauração. A partir da delimitação da área, das possíveis técnicas e indicadores, é indicada a elaboração de uma proposta de intervenção de trechos degradados em ambientes urbanos, a fim de auxiliar políticas públicas de municípios. Nesse sentido, o objetivo geral desse trabalho foi realizar um referencial teórico sobre restauração de matas ciliares na Bacia Hidrográfica Amazônica e uma caracterização do Igarapé Chico Reis localizado no município de Rorainópolis, estado de Roraima, bem como, uma proposta de intervenção para quatro trechos degradados do Igarapé localizado dentro do município.
\end{abstract}

Palavras-chave: Recuperação de áreas degradadas; Bacia hidrográfica Amazônica; Indicadores de restauração.

\begin{abstract}
Among the Hydrographic Basins present in Brazil, the Amazon Hydrographic Basin stands out. To maintain the integrity of this basin, as well as the availability and quality of water, it is necessary to conserve the strips of native vegetation that border its water bodies, called riparian forests. In this region, urban occupation took place in the vicinity of water bodies, in an irregular and disordered manner. This situation increases the chance of flooding and landslides on the banks of rivers caused by the removal of riparian forests. Several municipalities that are located in the Amazon River Basin are in these conditions, for example, in the municipality of Rorainópolis-RR. Some stretches of Igarapé Chico Reis, the main water body that cuts through the city of Rorainópolis, are in a process of degradation, making restoration essential. Several restoration techniques can be applied in degraded riparian forests, as well as the use of indicators to assess restoration success. From the delimitation of the area, the possible techniques and indicators, the elaboration of a proposal for the intervention of degraded stretches in urban environments is indicated, in order to assist public policies in municipalities. In this sense, the general objective of this work was to carry out a theoretical framework on the restoration of riparian forests in the Amazon River Basin and to characterize the Igarapé Chico Reis located in the municipality of Rorainópolis-RR, as well as an intervention proposal for four stretches degraded areas of the Igarapé located within the municipality.
\end{abstract}

Keywords: Recovery of degraded areas; Amazon hydrographic basin; Restoration indicators. 


\begin{abstract}
Resumen
Entre las Cuencas Hidrográficas presentes en Brasil, se destaca la Cuenca Hidrográfica del Amazonas. Para mantener la integridad de esta cuenca, así como la disponibilidad y calidad del agua, es necesario conservar las franjas de vegetación nativa que bordean sus cuerpos de agua, denominados bosques de ribera. En esta región, la ocupación urbana se produjo en las cercanías de cuerpos de agua, de manera irregular y desordenada. Esta situación aumenta la posibilidad de inundaciones y deslizamientos de tierra en las riberas de los ríos provocados por la remoción de bosques ribereños. Varios municipios que se ubican en la cuenca del río Amazonas se encuentran en estas condiciones, por ejemplo, en el municipio de Rorainópolis-RR. Algunos tramos de Igarapé Chico Reis, el principal cuerpo de agua que atraviesa la ciudad de Rorainópolis, se encuentran en proceso de degradación. Varias técnicas de restauración pueden aplicarse en bosques ribereños degradados, así como el uso de indicadores para evaluar el éxito de la restauración. A partir de las posibles técnicas e indicadores, se indica la elaboración de una propuesta de intervención de tramos degradados en entornos urbanos, con el fin de ayudar a las políticas públicas en los municipios. El objetivo general de este trabajo fue realizar un marco teórico sobre la restauración de bosques ribereños en la cuenca del río Amazonas y caracterizar el Igarapé Chico Reis ubicado en el municipio de Rorainópolis-RR, así como una propuesta de intervención para cuatro tramos de áreas degradadas del Igarapé ubicados dentro del municipio.
\end{abstract}

Palabras clave: Recuperación de áreas degradadas; Cuenca hidrográfica del Amazonas; Restaurar indicadores.

\title{
1. Introdução
}

A água desenvolve papel fundamental na manutenção da vida na Terra. Nesse aspecto, deve ser ressaltada a importância das Bacias Hidrográficas presentes no Brasil, especialmente a Bacia Hidrográfica Amazônica. Moura et al. (2021) afirmam que a Bacia Hidrográfica Amazônica é a mais importante e extensa do planeta em termos de área de drenagem e vazão. Além disso, a bacia hidrográfica interliga os recursos e elementos naturais como, por exemplo, a água, vegetação, clima e solo entre si e com as comunidades locais (Aquino et al., 2012). No entanto, de acordo com esses autores, a água é considerada um bem finito e vulnerável.

Para manutenção da integridade da bacia, bem como da disponibilidade de água, é necessário a conservação das faixas de vegetação nativa que margeiam os corpos d’água, denominadas de matas ciliares. Essas vegetações desempenham papel importante no ambiente como, por exemplo, na manutenção da qualidade da água, estabilidade dos solos, regularização dos ciclos hidrológicos e conservação da biodiversidade (Reis e Rogalski, 2006). Além disso, as matas ciliares funcionam como corredores ecológicos que interligam várias áreas, melhorando a qualidade ambiental e prestação de serviços ambientais locais (Aquino et al., 2012). No entanto, quando há ruptura desses corredores ecológicos pela ação antrópica, esses serviços serão interrompidos acarretando interferência no desenvolvimento e propagação de espécies animais e vegetais (Kutzmy et al., 2019).

Na região da Bacia Hidrográfica Amazônica, a ocupação urbana ocorreu nas áreas adjacências dos corpos hídricos (Medeiros et al., 2020). De acordo com esses autores, essa ocupação, em sua maioria, ocorreu de forma irregular e desordenada, acarretando em maiores chances de inundações, desbarrancamentos e erosões nas margens dos rios ocasionadas pela retirada das matas ciliares. Essa realidade também é encontrada no município de Rorainópolis, no estado de Roraima, onde são relatados vários problemas ambientais e sociais desencadeados pela retirada das faixas de vegetação que margeiam os corpos hídricos presentes no município (Oliveira et al., 2012; Souza e Barni, 2018).

O Igarapé Chico Reis é um dos principais cursos d’água presente no município de Rorainópolis. Estudos têm revelado que o Igarapé Chico Reis se encontra em processo de degradação devido à ocupação desordenada do solo e degradação de suas matas ciliares (Oliveira et al., 2012; Veras et al., 2012; Souza e Barni, 2018), se tornando essencial a restauração desse Igarapé.

A restauração é entendida como uma ação que visa recuperar a integridade e sustentabilidade de um local degradado o mais próximo da sua condição original (Society for Ecological Restoration - SER, 2004; Lima et al., 2015). Existem diversas técnicas para restauração de matas ciliares e a escolha da melhor técnica se dá a partir dos objetivos e metas traçados para o projeto de restauração (Lima et al., 2015). Para avaliar o sucesso das diversas técnicas, bem como do projeto de restauração é 
utilizado ferramentas avaliativas, denominados de indicadores ecológicos.

Antes da concretização de projetos de recuperação/restauração de matas ciliares em ambientes urbanos, podem ser realizadas propostas de intervenção para divulgação de informações quanto à situação de degradação das matas ciliares presentes nos municípios, possíveis técnicas de recuperação cabíveis de uso, bem como, ferramentas de avaliação do sucesso de projeto de recuperação/restauração das matas ciliares (Paranhos, 2012; Santos, 2018; Silva, 2018). Para isso, Santos (2018) indica que seja usada uma "Chave para tomada de decisão Recuperação de Áreas Degradadas" para auxiliar na elaboração da proposta de intervenção para matas ciliares degradadas em ambientes urbanos.

Nesse sentido, o objetivo geral desse trabalho foi realizar um referencial teórico sobre restauração de matas ciliares na Bacia Hidrográfica Amazônica e uma caracterização do Igarapé Chico Reis localizado no município de Rorainópolis, estado de Roraima, bem como, uma proposta de intervenção para quatro trechos degradados do Igarapé localizado dentro do município.

\section{Metodologia}

A condução dessa pesquisa de referencial teórico foi realizada de maneira sistemática, informativo e exploratório, conforme sugerido por Dornelas et al. (2021), de forma a identificar, avaliar e interpretar pesquisas, dados e resultados que estão associados ao objetivo do trabalho (Oliveira Júnior e Pasqualotti, 2021). Para isso, foram selecionados artigos científicos, livros, dissertações, teses, anais de congressos e dados oficiais de entidades governamentais relevantes ao tema.

Para elaboração de proposta de restauração, foi utilizada uma "Chave de Tomada de Decisão para Recuperação de Áreas Degradadas" conforme proposto por Santos (2018). A chave de tomada de decisão foi elaborada pela Resolução SMA n. 8 de 2008 (Secretaria do Meio Ambiente - SMA/SP, 2008), onde são fixadas orientações para o reflorestamento heterogêneo de áreas degradadas. A chave consta com 11 níveis, sendo eles:

1 - Sem remanescente florestal;

2 - Área abandonada (2a) ou área utilizada (2b);

3 - Solo não degradado (3a) ou solo degradado (3b);

4 - Solos não inundados (4a) ou solos inundados ou mal drenados (4b);

5 - Com regenerantes naturais (5a) ou sem regenerantes naturais (5b);

6 - Sem exposição de rocha (6a) ou com exposição de rocha (6b);

7 - Em área de pecuária (7a) ou não (7b);

8 - Pastagem com regenerantes (8a) ou sem (8b);

9 - Área de plantio florestal comercial (9a) ou área agrícola (9b);

10 - Com regenerantes naturais (10a) ou sem regenerantes naturais (10b); e

11 - Pouco tecnificada (11a) ou altamente tecnificada (11b).

\section{Desenvolvimento}

\subsection{Bacia Hidrográfica Amazônica}

Bacia Hidrográfica é definida como uma área de absorção natural da precipitação que converge o escoamento para um único ponto de saída (Agência Nacional de Águas - ANA, 2020). De acordo com Marcuzzo (2017), as bacias hidrográficas no Brasil podem ser divididas em oito: Bacia Hidrográfica do Atlântico - Trecho Sudeste; do Rio Uruguai; do Rio Paraná; do Atlântico - Trecho Leste; do Rio São Francisco; do Atlântico - Trecho Norte/Nordeste; do Rio Tocantins; e do Rio Amazonas (Figura 1). 
Figura 1: Bacias Hidrográficas presente no Brasil.

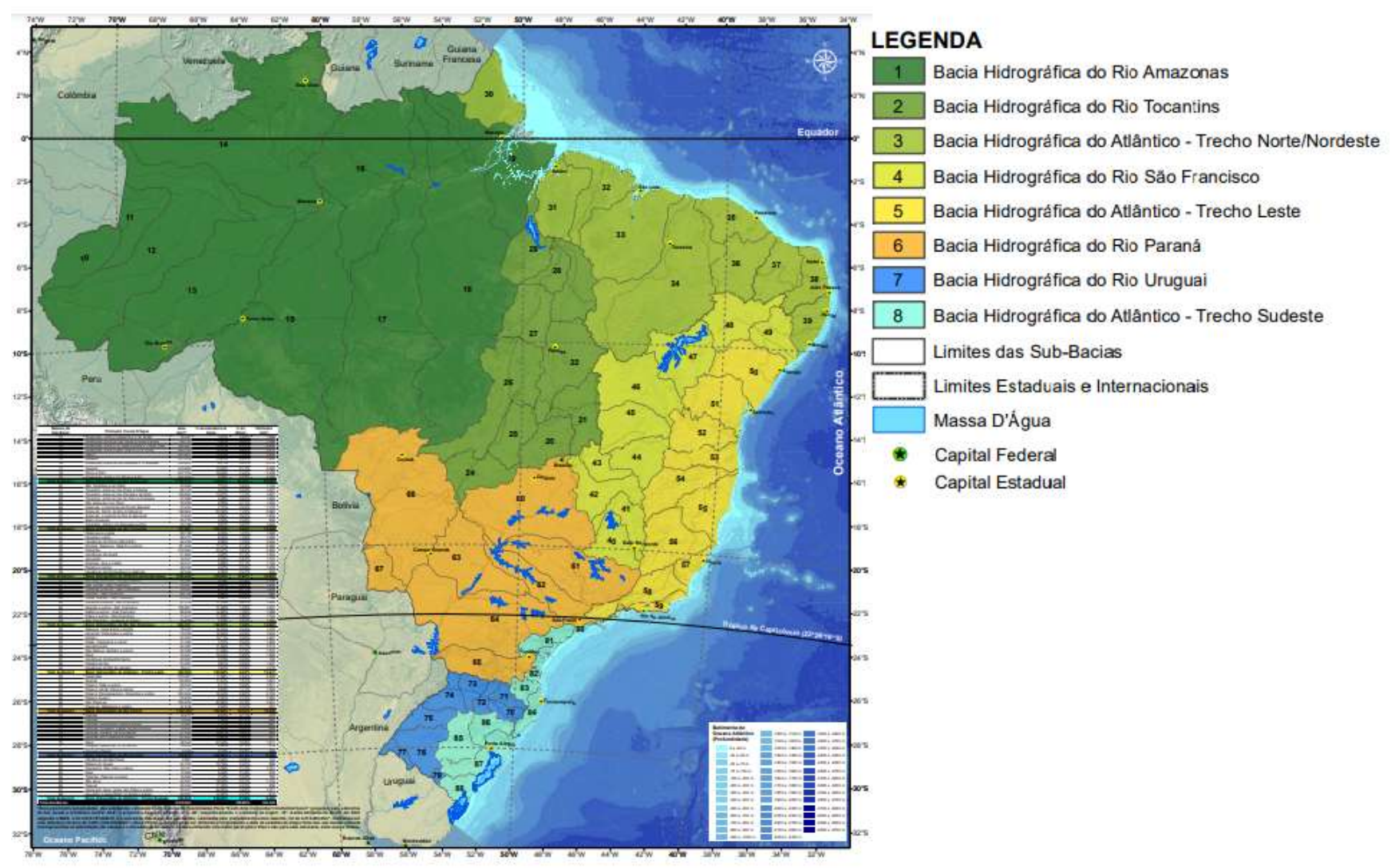

Fonte: Adaptado de Marcuzzo (2017).

A Bacia Hidrográfica do Rio Amazonas está localizada no norte da América do Sul e compreende um total de 6,8 milhões de $\mathrm{Km}^{2}$ (Wittmann e Junk, 2016), sendo considerada a maior bacia do planeta. O clima da região pode variar de tropical úmido a clima montanhoso ártico, com precipitação pluviométrica anual de $2.460 \mathrm{~mm} / \mathrm{ano}$ (Silva, 2013). A Bacia Hidrográfica do Rio Amazonas é formada por rios, lagos e igarapés (Lima et al., 2021). Os igarapés são caracterizados como cursos d'água de pequeno porte encoberto pelo dossel das matas ciliares (Corrêa et al., 2012).

Nesse sentido, a Bacia Amazônica está presente em seis estados brasileiros: Acre, Amapá, Amazonas, Pará, Tocantins, Rondônia e Roraima (Marcuzzo, 2017; Coutinho et al., 2019). Particularmente no estado de Roraima, pode ser destacado a sub-bacia do Rio Branco, maior e mais importante do estado, com extensão de $45.530 \mathrm{Km}^{2}$ e afluente do Rio Negro (Roraima, 2019). Além disso, podem ser elencados alguns rios que ocorrem em seu território, como: Água Boa do Univiní, Ailã, Ajarani, Alalaú, Branco, Catrimani, Cauamé, Itapará, Mucajaí, Surumu,Tacutu, Uraricoera, Urubu e Xeruini (Roraima, 2019). As áreas inseridas na Bacia apresentam variação quanto à cobertura do solo, fertilidade da água e do solo, diversidade de plantas e animais (Wittmann e Junk, 2016). De acordo com esses autores, estão inseridas na Bacia Hidrográfica da Amazônia: i) planícies aluviais; ii) áreas inundadas; iii) savanas; iv) manguezais; v) matas ripárias (matas ciliares), dentre outros. Além disso, a região amazônica também pode ser dividida em três tipos de categorias de vegetação: i) matas de terra firme (regiões altas que não são inundadas por rios); ii) matas de igapó (regiões baixas que são frequentemente inundadas); e iii) matas de várzea (passam por inundações em determinadas épocas do ano) (Embrapa, 2021).

No entanto, historicamente, essas formações vegetacionais vêm sendo exploradas desenfreadamente na região da Amazônia, caracterizado pela ausência de práticas conservacionistas voltadas a sustentabilidade, o que acarretou em vários impactos negativos na bacia hidrográfica, como perda da qualidade do solo, erosões hídricas e redução de oferta hídrica 
(Pereira et al. 2016). Desta forma, pode-se afirmar que a redução de oferta hídrica, acarretado pelo desmatamento, reduz o regime hídrico da bacia, proporcionando um maior nível de lençol freático, maior escoamento superficial, alteração de deflúvios de rios e qualidade da água (Carvalho et al., 2012). Além disso, a Bacia Hidrográfica Amazônica se comporta como um sumidouro de umidade da atmosfera, recebendo vapor d'água tanto do transporte de origem oceânica quanto da evapotranspiração da floresta por meio do processo de reciclagem de precipitação (Rocha et al., 2017).

Dada a sua relevância, é essencial buscar formas eficazes e eficientes para evitar degradação da Bacia Hidrográfica Amazônica. Uma das formas para evitar essa degradação é através da preservação das matas que acompanham os corpos hídricos, como por exemplo, as matas ciliares nos igarapés. De acordo com Figueiredo et al. (2020) é essencial a preservação das matas ciliares nos igarapés da Amazônia. Esses autores explicam que a preservação das matas ciliares irão mitigar impactos causados pelas mudanças da terra na bacia hidrográfica, bem como, irá auxiliar na conservação da qualidade da água, dos ecossistemas aquáticos, volume de água nos rios e, consequentemente, na qualidade de vida.

\subsection{Matas Ciliares}

As matas ciliares são definidas como formações vegetacionais que margeiam os corpos hídricos e apresentam particularidades em função da regulamentação do fluxo de água, de sedimentos e de nutrientes (Gonçalves et al. 2005; Lima et al. 2016). São chamadas de matas ciliares pela sua importância para a proteção dos rios, atuando como uma espécie de cílios na proteção dos corpos hídricos. Essas áreas, tanto em ambiente rural quanto urbano, são consideradas como Áreas de Preservação Permanente (APP) de acordo com a Lei no 12.651 de 2012 (Brasil, 2012) e por isso, devem ser preservadas.

Em um contexto geral, do ponto de vista ecológico e hidrológico, as matas ciliares são essências para o equilíbrio, manutenção e resiliência da Bacia Hidrográfica (Lima, 2014). Além disso, de acordo com esse autor, também agem na contenção de enxurradas e retenção de agrotóxicos. Outro fator de importância das matas ciliares é que atuam como corredores ecológicos. Kuntschik et al. (2014) afirma que as matas presentes ao longo dos cursos conectam fragmentos de matas próximas, proporcionando passagem aos animais e facilitam a disseminação de sementes.

No entanto, em ambiente rural, as matas ciliares presentes nos biomas brasileiros, incluindo na região Amazônica, representam para muitos agricultores e pecuaristas como um obstáculo ao acesso à água, o que pode acarretar na degradação dessas áreas (Lima, 2014). Além disso, outras atividades também influenciam na degradação das matas ciliares, como, por exemplo: incêndios, extração de areia nos rios, empreendimentos turísticos mal planejados (Ribeiro, 2013), corte seletivo de madeira, mineração e pastagem (Attanasio et al., 2012), dentre outros. Ribeiro (2013) alerta que essas atividades devem ser evitadas, uma vez que toda forma de vida depende de água e, dessa forma, é necessário preservar as nascentes e as matas ciliares.

De acordo com Lima et al. (2015), a degradação desses ecossistemas e dos serviços ecossistêmicos fornecidos pelas matas ciliares, compromete o funcionamento de ecossistemas associados. Especificamente em áreas urbanas, deve ser ressaltado que cidades e municípios brasileiros são caracterizados, em sua maioria, pela ausência total de faixas de proteção dos corpos hídricos conferidas pelas matas ciliares (Castro et al., 2018). De acordo com esses autores, esse fato pode ser explicado, pois antes da Lei 12.651 de 2012, existiam inúmeras interpretações e incertezas quanto à preservação dessas áreas em contexto urbano, o que acarretou na ocupação desordenada dessas APPs.

Na região da Bacia Hidrográfica Amazônica, a ocupação urbana ocorreu nas adjacências de corpos hídricos (Medeiros et al., 2020) que compõem essa bacia. Esse fato pode ser explicado, pois a migração da população rural e ribeirinha na região amazônica em busca de melhor qualidade de vida acarretaram em invasões e ocupações irregulares das matas ciliares e outras APPs em núcleos urbanos (Medeiros et al., 2020). Ainda de acordo com esses autores, as diminuições das faixas de matas ciliares em ambientes urbanos aumentam as chances de inundações, desbarrancamentos e erosões nas margens dos rios, 
colocando em risco os habitantes desses locais. No município de Rorainópolis, no estado de Roraima, também é encontrada essa realidade (Souza e Barni, 2018), o que acarretou em vários problemas ambientais e sociais (Oliveira et al., 2012).

Desta forma, pode-se afirmar que a preservação e recuperação dessas áreas é a melhor opção na proteção dos recursos hídricos, bem como para a manutenção da biodiversidade (Lima et al., 2016) e na melhoria de qualidade de vida.

\subsection{Igarapé Chico Reis, Rorainópolis - RR}

O município de Rorainópolis pertence ao Bioma Amazônico é um dos 15 municípios do estado de Roraima. Está situada às margens da BR 174 e localizada a 261 km da capital de Roraima, Boa Vista e 488 km de Manaus - AM. Devido a essa condição, se destaca por seu posicionamento estratégico como ponto logístico central entre essas capitais (Senhoras e Nascimento, 2020).

A criação do município de Rorainópolis se deu a partir da instalação de uma sede do Instituto Nacional de Colonização e Reforma Agrária - INCRA, na década de 1970, com o objetivo de distribuir terras na região, o que atraiu inúmeras pessoas de todas as regiões do país (Rorainópolis, 2021). Antes conhecida como Vila do INCRA, Rorainópolis só virou munícipio em 1995 (Instituto Brasileiro de Geografia e Estatística - IBGE, 2017) e atualmente é considerado o segundo município mais populoso do estado de Roraima, atrás da capital Boa Vista (Oliveira et al., 2012), com uma população estimada em 31.387 habitantes (IBGE, 2021).

Dentre os rios que compõem a hidrografia do município de Rorainópolis, podem ser exemplificados: Alalaú, Branco, Anauá e Jauaperí (Plano Territorial de Desenvolvimento Rural Sustentável - PTDRS, 2010), que integram a Bacia Hidrográfica Amazônica. O clima da região é caracterizado como Af de acordo com classificação de Koppen, precipitação variando de 1.900 a $2.200 \mathrm{~mm}$ e temperatura média anual de $27^{\circ} \mathrm{C}$ (Souza e Barni, 2018).

Atualmente, o município de Rorainópolis vem se expandindo de forma acelerada e desordenada (Barni et al., 2015), acarretando em inúmeros problemas sociais e ambientais. Oliveira et al. (2012), Veras et al. (2012) e Barni et al. (2015) chamam a atenção da precariedade de alguns serviços públicos presentes em Rorainópolis como, por exemplo, ligados a saneamento básico, destinação correta de resíduos sólidos e degradação das matas ciliares do Igarapé Chico Reis, que atravessa a área urbana do município.

O Igarapé Chico Reis (Figura 2) é considerado como um dos principais cursos d’água presente no município de Rorainópolis e de acordo com Oliveira et al. (2012), o Igarapé Chico Reis é afluente do Igarapé Gentil. No interior do município, existem trechos canalizados do Igarapé Chico Reis, conforme relatado por Molinari et al. (2011). De acordo esses autores, esses trechos ocorrem nas áreas centrais da cidade onde são observadas assoreamento dos canais, presença de gramíneas invasoras e, quando no verão, aparecimento de ratos, pernilongos e doenças transmitidas por vetores. 
Research, Society and Development, v. 10, n. 15, e341101522816, 2021

(CC BY 4.0) | ISSN 2525-3409 | DOI: http://dx.doi.org/10.33448/rsd-v10i15.22816

Figura 2: Localização do Igarapé Chico Reis, Rorainópolis, Roraima, Brasil
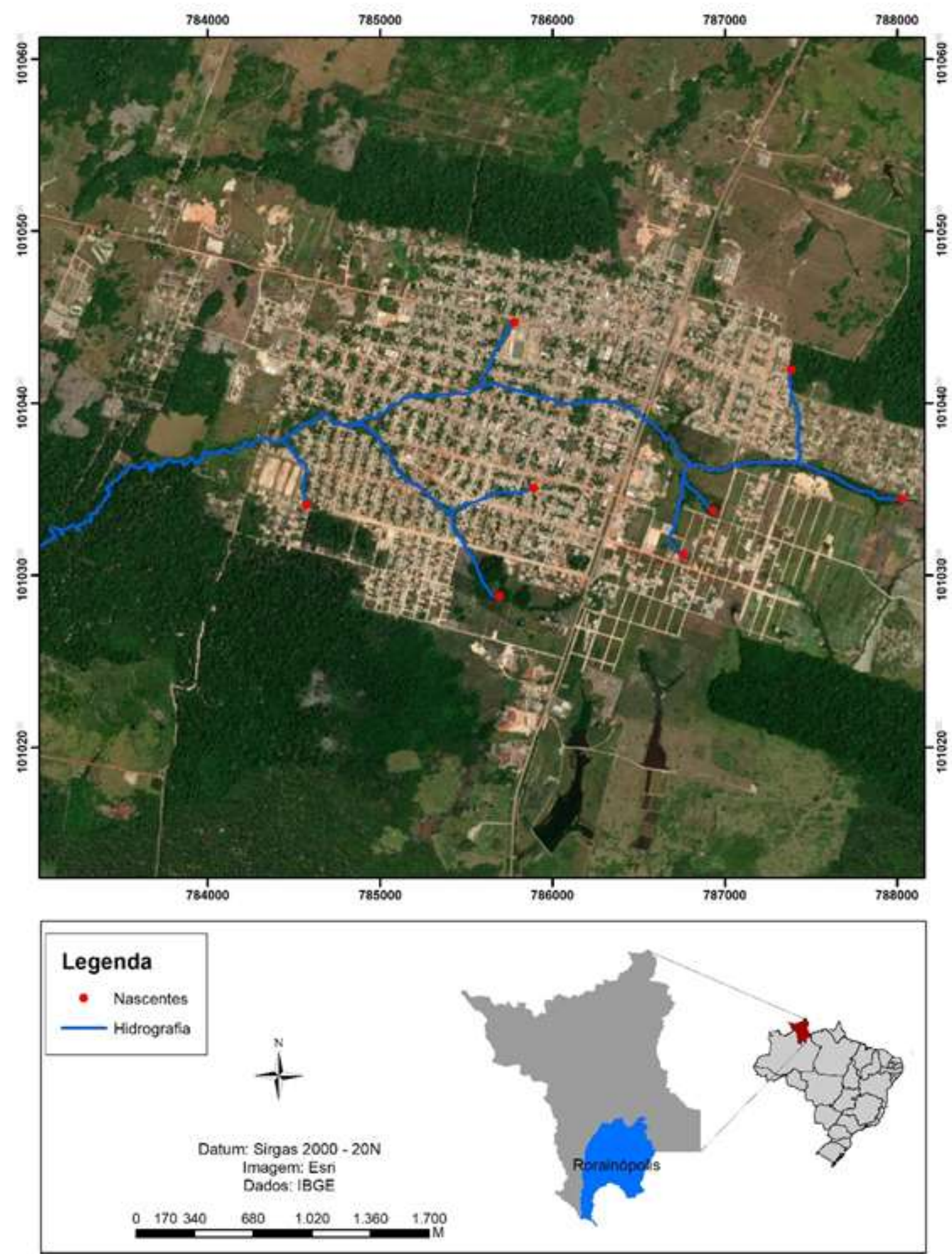

\section{Igarapé Chico Reis}

Fonte: Autores.

Veras et al. (2012) avaliando a dinâmica sócio espacial do município de Rorainópolis, concluíram que as margens Igarapé Chico Reis estão em processo de degradação, devido as atividades antrópicas, falta de saneamento básico e, 
principalmente, pelo desmatamento das matas ciliares. Esses autores afirmam que um dos métodos para sanar essas problemáticas é através da educação ambiental, de modo a sensibilizar as pessoas do município sobre a importância do Igarapé Chico Reis, bem como, no entendimento da dinâmica de uso e preservação das matas ciliares.

Outros estudos também comprovam a ocupação e desmatamento das áreas de matas ciliares do Igarapé Chico Reis no município de Rorainópolis. Souza e Barni (2018), realizando a análise espacial da Área de Preservação Permanente (APP) do Igarapé Chico Reis em Rorainópolis, concluíram que pelo menos em 22,5\% das APPs há disfunção no uso e ocupação dos solos. Oliveira et al. (2012), analisando indicadores da qualidade da água no município de Rorainópolis, afirmam que o desmatamento das matas ciliares no Igarapé Chico Reis se dá principalmente pelo processo de urbanização do município. Além disso, esses autores concluíram que a água do Igarapé Chico Reis estava poluída por diversos fatores, como por exemplo, devido ao desmatamento das matas ciliares, bem como despejos impróprios de resíduos ao longo do igarapé. Marques e Oagin (2006), analisando a poluição do Igarapé Chico Reis em diferentes pontos do município de Rorainópolis e suas consequências para a saúde pública, concluíram que em algumas épocas do ano, como no inverno, o desmatamento das matas ciliares em alguns pontos do município bem como o despejo de resíduos sólidos no corpo hídrico acarretam problemas no fluxo e volume de água do igarapé, ocasionando em enchentes e doenças aos moradores de Rorainópolis.

Nesse sentido, deve-se ser ressaltada a importância da preservação do Igarapé Chico Reis para a biodiversidade local, bem como, para saúde pública. Oliveira et al. (2012) chamam a atenção da necessidade de pesquisas que avaliem condições ambientais desse município, principalmente pelos problemas sociais e econômicos que impactam essa região.

No entanto, como discutido anteriormente, a realidade encontrada para as matas ciliares no Igarapé Chico Reis é a mesma encontrada em outros corpos hídricos presente em outros centros urbanos no Brasil, incluindo na região amazônica. A preservação das matas ciliares, bem como a restauração do Igarapé Chico Reis irá auxiliar no fluxo e volume da água, bem como, conservar a sua qualidade, melhorando a qualidade de vida da população.

\subsection{Restauração ecológica e Técnicas de Recuperação de áreas Degradadas}

De acordo com o Decreto Federal n. 97.632 de 1989 (Brasil, 1989) degradação é o processo resultante dos danos ao meio ambiente, pelos quais se perdem ou se reduzem algumas de suas propriedades, como por exemplo, a qualidade ou capacidade produtiva dos recursos ambientais; enquanto recuperação é o retorno do sítio degradado a uma forma de utilização, de acordo com um plano pré-estabelecido para o uso do solo, visando a obtenção de uma estabilidade do meio ambiente. No estado de Roraima, por exemplo, estima-se que existam 10 mil hectares de Áreas de Preservação Permanente (APP) que precisam ser recuperadas ou restauradas (Validacar, 2019). No entanto, para recomposição de uma área degradada, é necessário, primeiramente, saber quais são objetivos finais do projeto, para i) recuperar, ii) reabilitar ou iii) restaurar, conforme descrito por Lima et al. (2015).

Recuperação é entendida como a "restituição de um ecossistema ou de uma população silvestre degradada a uma condição não degradada, que pode ser diferente da sua condição original" (Brasil, 2000). Restauração é a "restituição de um ecossistema ou de uma população silvestre degradada o mais próximo possível da sua condição original" (SER, 2004). Reabilitação é habilitar um ecossistema degradado para algum tipo de uso (Sánchez, 2020), como por exemplo, a implantação de uma atividade que renderá lucro, ou atividades menos tangíveis em termos monetários, visando, por exemplo, a recreação ou a valorização estético-ecológica (Tavares, 2008).

A melhor forma para se recuperar uma vegetação nativa que margeia os corpos hídricos é através da restauração ecológica (Lima et al., 2015). De acordo com esses autores, a restauração ecológica é uma ação que visa: i) recompor comunidades ecologicamente viáveis, ii) resgatar uma relação mais sustentável entre o homem e a natureza e iii) recuperar a integridade e sustentabilidade do local. Além disso, Castro et al. (2012) afirmam que a restauração ecológica viabiliza a 
manutenção dos ecossistemas em longo prazo, estabelecendo comunidades bióticas similares às que ocorriam naturalmente na região.

Nesse sentido, para que o processo de restauração tenha sucesso, Aquino et al. (2012) estabelecem algumas etapas que devem ser seguidas em áreas a serem restauradas:

Etapa 1: Cercar ou proteger a área;

Etapa 2: Eliminar as causas de perturbação, como lixos e pisoteamento;

Etapa 3: Combate a possíveis incêndios;

Etapa 4: Promover interligação com remanescentes nativas da região;

Etapa 5: Controle de gramíneas exóticas que competem com as plantas nativas;

Etapa 6: Escolha do sistema de restauração mais adequado para a área (regeneração natural ou restauração induzida);

Etapa 7: No caso de plantio de mudas, na restauração induzida, deve ser escolhido espécies nativas das matas que margeiam os corpos hídricos, priorizando frutíferas que atraiam animais. Os animais são essenciais para aumentar a biodiversidade do local, pois trazem sementes de diferentes lugares e auxiliam na recuperação de áreas degradadas;

Etapa 8: No caso de plantio de mudas, na restauração induzida, devem ser distribuídas de acordo com sua habitabilidade; e

Etapa 9: Envolver a comunidade local no monitoramento e cuidado com o local em processo de restauração.

Os sistemas de restauração das matas ciliares são a partir da regeneração natural ou da restauração induzida (Aquino et al., 2012) e a escolha do sistema a ser empregado varia conforme o grau de degradação da área. A regeneração natural visa, a partir do isolamento da área, a retomada dos processos naturais de restauração sem que haja o plantio de mudas e/ou sementes pelo homem (Oliveira, 2018). Para que uma área seja considerada capaz de se regenerar devem-se observar vários fatores, como por exemplo: sementes remanescentes no solo, presença de pequenas plantas nativas, pouca perturbação, solo conservado e sem compactação, dentre outros (Aquino et al., 2012).

Por outro lado, a restauração induzida consiste em várias ações que promovam o retorno da vegetação e da fauna na área degradada (Aquino et al., 2012). Na restauração induzida, esses autores estabelecem alguns critérios que devem ser obedecidos para que haja sucesso na restauração, como a seleção correta de espécies para o plantio, preparo do solo, controle de plantas daninhas, controle de formigas, abertura e adubação de covas e a utilização de técnica correta de restauração.

Algumas técnicas de restauração induzidas são (Castro et al., 2012):

i) Adubação verde: utiliza uma ou mais espécies vegetais que cumpram a função de proteger e nutrir o solo, gerando melhores condições e acelerando regeneração natural.

ii) Ilhas de diversidade: consiste no plantio de mudas em pequenos núcleos (ilhas) com alta diversidade e alta densidade de indivíduos.

iii) Plantio em linhas: é o plantio de espécies por toda a extensão da área a ser restaurada, podendo ser feito através de semeadura direta ou plantio de mudas, em que são realizadas combinações de espécies dos diferentes grupos ecológicos.

iv) Nucleação: tem objetivo de criar pequenos hábitats que propiciem incremento das interações interespecíficas, planta-planta, plantas-microorganismos, plantasanimais, diferentes níveis de predação e associações e os processos reprodutivos das plantas de polinização e dispersão de sementes.

Algumas técnicas nucleadoras são: eleiramento de galhos, transposição de solo/serapilheira, poleiros artificiais e plantio em ilhas (Aquino et al., 2012). Porto et al. (2019) afirmam que na escolha da técnica de restauração a ser empregada, é necessária uma visão holística, devendo-se levar em conta que esses sistemas não podem ser considerados de forma isoladas e as intervenções devem seguir uma visão mais ampla e integradora, que considerem fatores biológicos e geológicos.

Nesse sentido, alguns trabalhos avaliaram a recuperação da vegetação que margeiam corpos hídricos em ambiente 
urbano. Fernandes e Andrade (2017), analisando o Plano de Recuperação de Recuperação do Igarapé Patauateua, manancial urbano que está localizado no município de São Miguel do Guamá, no estado do Pará, averiguou que a recuperação desse igarapé foi a partir de plantio de mudas nativas, sem o estabelecimento de uma técnica específica. As espécies selecionadas para recuperar essa área foram as que ocorriam frequentemente naquele espaço: Euterpe oleracea Mart. (Açaí), Bactris gasipaes Kunth (Pupunha), Mauritia flexuosa L. f. (Buriti), Pouteria guianensis Aubl. (Abiu), Caryocar villosum (Aubl.) Pers. (Piquiá), Carapa guianensis Aubl. (Andiroba), Inga edulis Mart (Ingá Cipós), dentre outros. Além disso, vale ressaltar que o Igarapé Patauateua, no momento do estudo, se encontrava em condições similares ao Igarapé Chico Reis: trechos de vegetação degradados devido à urbanização do município São Miguel do Guamá e, consequentemente, comprometimento dos cursos fluviais.

Conegundes (2018) avaliando nascentes urbanas das Bacias Hidrográficas dos Ribeirões Arrudas e Onça propôs algumas técnicas de recuperação, como por exemplo, o cercamento da área para condução da regeneração natural, bem como o plantio de mudas nativas e frutíferas, de espécies pioneiras, secundárias e clímax. Além disso, esse autor elenca algumas outras medidas realizadas no local, como: capina seletiva, retirada de entulhos, etc. Costa Filho (2016) propondo um Plano de Recuperação de Área Degradada de um trecho de APP do córrego Pipa no município de Aparecida de Goiânia, estado de Goiás, indica o plantio de mudas para a recomposição da área degradada. Nesse trabalho, Costa Filho (2016) não relata uma técnica especifica, porém, faz algumas sugestões, como por exemplo: as espécies utilizadas devem ser nativas e representativas da região, utilização de $80 \%$ de espécies pioneiras e secundárias, utilização de espécies frutíferas, dentre outros.

Santos (2018) avaliando a Várzea do Rio Tietê, propõe algumas técnicas de restauração para as áreas degradadas, como a adubação verde e a transferência do solo de local preservado para o local degradado. A técnica de transferência de solo consiste na coleta de porções superficiais do solo, com presença de folhas, sementes, galhos e raízes em decomposição que são depositadas na área degradada e auxiliam no processo de restauração, principalmente pela presença de sementes e organismos, como bactérias, cupins, formigas, etc. (Aquino et al., 2012). Além disso, Santos (2018) propõe o plantio de mudas ou semeadura no local degradado. De acordo com essa autora, essas técnicas irão criar condições de recuperação gradativa do solo exposto, nutrindo esse solo e preparando-o para a recuperação da mata ciliar.

No entanto, na literatura são encontradas mais pesquisas relacionadas a técnicas de recuperação ou restauração das vegetações que margeiam os corpos d'água em ambiente rural em relação ao ambiente urbano. Três e Reis (2009), utilizaram transposição de solo, poleiros artificiais, banco e chuva de sementes como técnicas de restauração de mata ciliar localizada na cidade de Rio Negrinho, estado de Santa Catarina. A técnica de instalação de poleiros artificias (secos) consiste na construção de varas de bambus, estruturas de mourões de eucalipto, dentre outros, que servem para atrair os animais (Aquino et al., 2012).

Dalpizzol et al. (2021) analisando técnicas nucleadoras em uma Área de Preservação Permanente no Planalto Serrano, no estado de Santa Catarina, utilizaram a técnica de núcleos de Anderson para o plantio das mudas. Núcleos de Anderson é uma técnica baseada no modelo de plantio de mudas adensadas em grupos espaçados (Anderson, 1951). Lima et al. (2016) utilizaram diferentes técnicas de restauração de uma mata ciliar localizada no Distrito Federal: regeneração natural, poleiros artificiais, núcleos de Anderson e linhas de preenchimento associadas a linhas de diversidade. De acordo com Aquino et al. (2012), a técnica de linhas de preenchimento associadas a linhas de diversidade consiste na distribuição de mudas de rápido crescimento nas linhas de preenchimento, que proporcionam sombra e copas maiores que permitem o desenvolvimento das mudas instaladas na linha de diversidade. Ainda de acordo com esses autores, as linhas de diversidade são compostas por várias espécies, que podem não apresentar crescimento tão rápido, porém podem atrair a fauna pelos alimentos que fornecem, por exemplo.

Rezende (2016) avaliando a restauração de área de APP do Rio Madeira, no estado de Rondônia, avaliou a recomposição da área a partir da regeneração natural, plantios de mudas, semeadura direta e plantio de mudas associado à 
semeadura direta. Paumgasrtten (2018) utilizou a regeneração natural e o plantio de espécies nativas para analisar a restauração ecológica de mata ciliar dominada por pastagem no Nordeste do Pará.

Desta forma, é possível avaliar a variedade de técnicas que são usualmente utilizadas no Brasil como forma de restauração de matas ciliares, tanto em contexto rural quanto urbano. Durante a restauração de ambientes degradados, alguns parâmetros devem ser analisados periodicamente para averiguar o sucesso da restauração. Esses parâmetros podem ser chamados de indicadores ecológicos (Rodrigues et al., 2009; Prach et al., 2019).

\subsection{Indicadores da Restauração Ecológica}

O monitoramento é etapa essencial para avaliação dos objetivos e metas de um projeto de restauração de área degradada (Lima et al., 2015). De acordo com esses autores, com a ausência do monitoramento das áreas em processo de restauração, é impossibilitada a definição de novas estratégias ou manejo adaptativo de ações em função da situação a ser recuperada e dos objetivos propostos.

Durante o monitoramento, critérios avaliativos, ou indicadores, devem ser utilizados para averiguar diversos aspectos ambientais, bem como, o processo de restauração (Rodrigues et al., 2009). Além disso, de acordo com esses autores, com a utilização de indicadores é possível fazer inferências sobre a evolução dos recursos bióticos e abióticos na área em restauração. Os valores obtidos pelos indicadores devem ser comparados aos estabelecidos nas metas do projeto (Martins, 2012), verificando se elas foram atingidas, bem como a viabilidade das técnicas e metodologias aplicadas (Lima et al., 2015).

Inúmeros parâmetros podem ser utilizados como indicadores na restauração, desde que consiga fornecer informações com exatidão e ter custos aceitáveis (Rodrigues e Leitão Filho, 2001). Lima et al. (2015) citam algumas características que devem ser consideradas para seleção dos indicadores:

i) Estar de acordo com os objetivos do projeto de restauração;

ii) Ser fácil mensuração;

iii) Ser prático e realista em relação aos custos de coleta;

iv) Ser de qualidade e confiabilidade;

v) Ser capaz de detectar alterações no ambiente;

vi) Ser usado em escalas espaciais e temporais;

vii) Permitir formulação de referências;

viii) Transmitir ganhos ambientais do projeto de restauração;

ix) Relacionar as metas dos projetos com os processos sucessionais naturais; e

x) Auxiliar na tomada de decisões.

Dessa forma, deve ser salientado que alguns indicadores podem ser mais práticos, ao mesmo tempo em que outros possam ser considerados mais caros ou necessidade de maior rigor de uso (Siqueira e Mesquita, 2007). Além disso, para a escolha do indicador adequado, deve ser levada em consideração a fase em que o projeto de restauração se encontra: fase de implantação (1 a 12 meses), fase pós-implantação (12 a 36 meses) e fase de vegetação restaurada (mais de 48 meses) (Rodrigues et al., 2009). Alguns indicadores que podem ser avaliados na fase de implantação do projeto de restauração são (Rodrigues et al., 2009; Rigueira e Mariano-Neto, 2013; Lima et al., 2015):

i) Presença de processos erosivos;

ii) Avaliação da cobertura vegetal;

iii) Presença e frequência de espécies invasoras;

iv) Presença e cobertura de regenerantes;

v) Taxa de sobrevivência de mudas plantadas; 
vi) Avaliação da altura e diâmetro de mudas plantadas;

vii) Chuva e banco de sementes;

viii) Avaliação química e física do solo;

ix) Profundidade da cova no plantio de mudas; e

x) Compactação e acidez do solo.

Desta forma, é fundamental o uso de indicadores em projetos de restauração, pois possibilita avaliar aos métodos empregados a fim de fornecer maior grau de segurança na recomendação técnica final (Lima et al., 2015). Além disso, é esperado que, com o uso de indicadores, a área, com o tempo, seja sustentável e consiga cumprir seu papel ecológico e florestal (Rodrigues e Leitão Filho, 2001).

\subsection{Proposta de intervenção}

Para elaboração da proposta de restauração de trechos degradados do Igarapé Chico Reis, se teve como base trabalhos de Paranhos (2012), Santos (2018) e Silva (2018). Para isso, foram selecionadas quatro situações onde a mata ciliar do Igarapé Chico Reis se encontra degradada (Figura 3). Os trechos (situações) foram escolhidos ao longo do curso do Igarapé Chico Reis a partir de duas perspectivas: situações onde o Igarapé se encontra canalizado (Figuras 4A e 4B) e onde o Igarapé não se encontra canalizado (Figuras 4C e 4D).

A partir da análise in loco, foi possível observar que todos os cenários necessitam de intervenção. Nas situações 1 e 2 (Figuras 4A e 4B), foi possível avaliar que os trechos do canal se encontram com alta densidade de cobertura de gramíneas exóticas em suas margens, bem como ao longo do seu curso, conforme já observado por Molinari et al. (2011). Em relação à presença de gramíneas exóticas em suas margens é possível afirmar que esse fato pode interferir na chegada e desenvolvimento de novas espécies nativas nessas áreas. Quanto à presença de gramíneas exóticas ao longo do canal do Igarapé, é possível afirmar que esse fato pode aumentar seu grau de assoreamento, bem como, diminuir a qualidade da água. Além disso, nota-se a ausência de espécies nativas, tanto arbustivas quanto arbóreas às margens dos trechos do canal, que é refletido pela alta densidade de cobertura de gramíneas. De acordo Molinari et al. (2011), esse canal apresenta, aproximadamente, $6 \mathrm{~m}$ de largura e $90 \mathrm{~cm}$ de profundidade. 
Figura 3: Trechos degradados escolhidos para proposta de intervenção no Igarapé Chico Reis, Rorainópolis, Roraima.

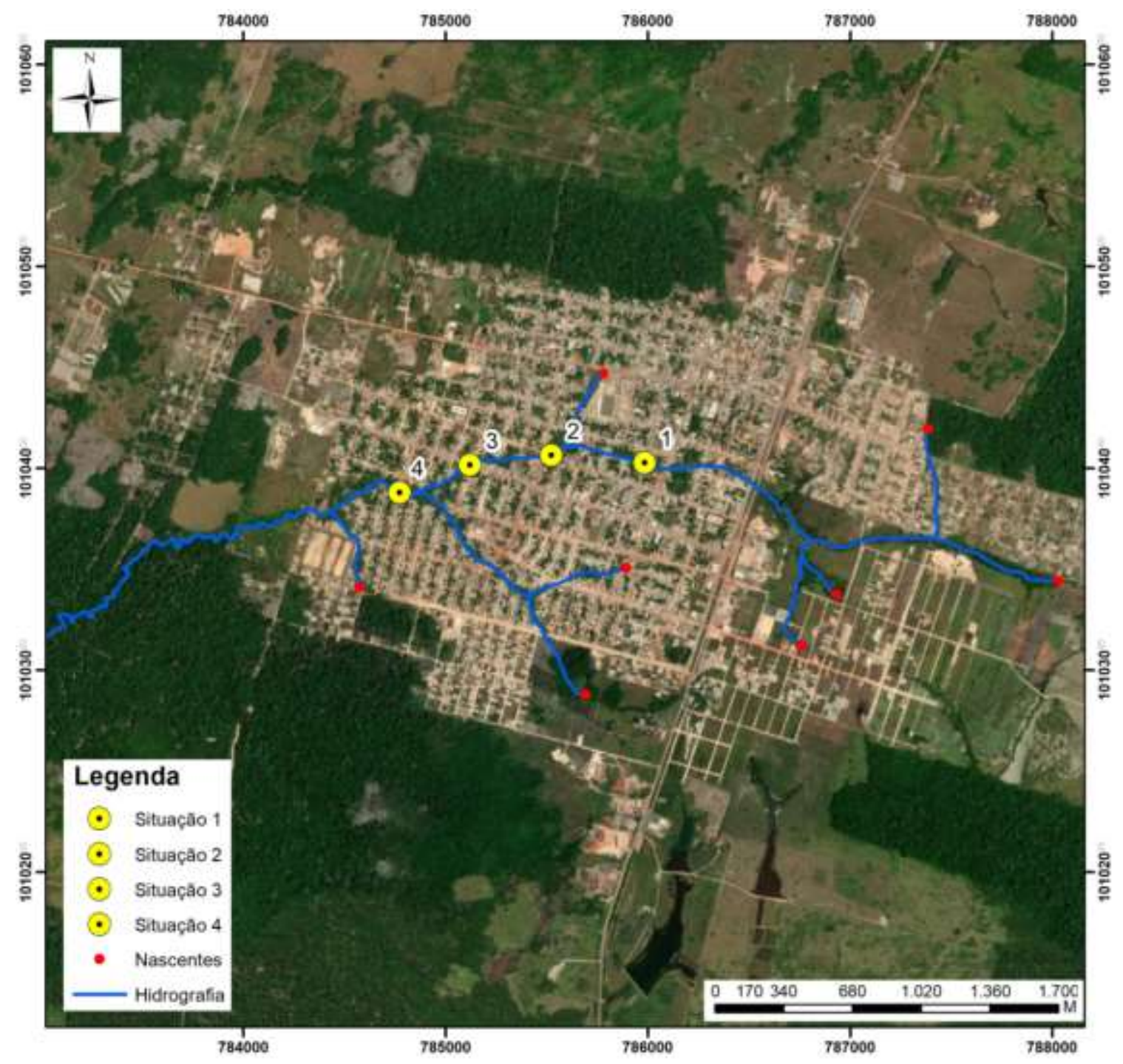

Fonte: Autores.

Nas situações 3 e 4 (Figuras 4C e 4D), é possível observar trechos do Igarapé assoreado e as margens com alta densidade de cobertura de gramíneas, solo exposto, além de ausência de espécies nativas. Vale ressaltar que, conforme relatado por Molinari et al. (2011), esses trechos assoreados do Igarapé Chico Reis, influenciam diretamente na saúde da população, devido ao aparecimento de ratos e pernilongos que transmitem doenças, principalmente no verão.

A partir da "Chave para tomada de decisão Recuperação de Áreas Degradadas" proposta por Santos (2018) foi possível estabelecer algumas intervenções. Para as situações 1 e 2, os níveis percorridos foram:

- 1b: Sem remanescente florestal

- 2a: Em área abandonada

- 3a: Em solo não degradado

- 4a: Não inundado

- 5b: Sem regenerantes naturais

Figura 4: Diferentes situações onde o Igarapé Chico Reis, Rorainópolis, Roraima, se encontra degradado. Onde: 4A: Situação 1 - Trecho do Igarapé Chico Reis, Rorainópolis-RR, canalizado e tomado por gramíneas; 4B: Situação 2 - Trecho do Igarapé Chico Reis, Rorainópolis-RR, canalizado e tomado por gramíneas, bem como suas margens; 4C: Situação 3 - Trecho do 
Igarapé Chico Reis, Rorainópolis-RR, assoreado, com presença de espécies invasoras nas margens e ao longo do curso d'água, além de solo exposto na mata ciliar; e 4D: Situação 4 - Situação 4 - Trecho do Igarapé assoreado e com presença de espécies invasoras nas margens e ao longo do curso d'água, além de solo exposto na mata ciliar.

Figura 4. Trecho do Igarapé.

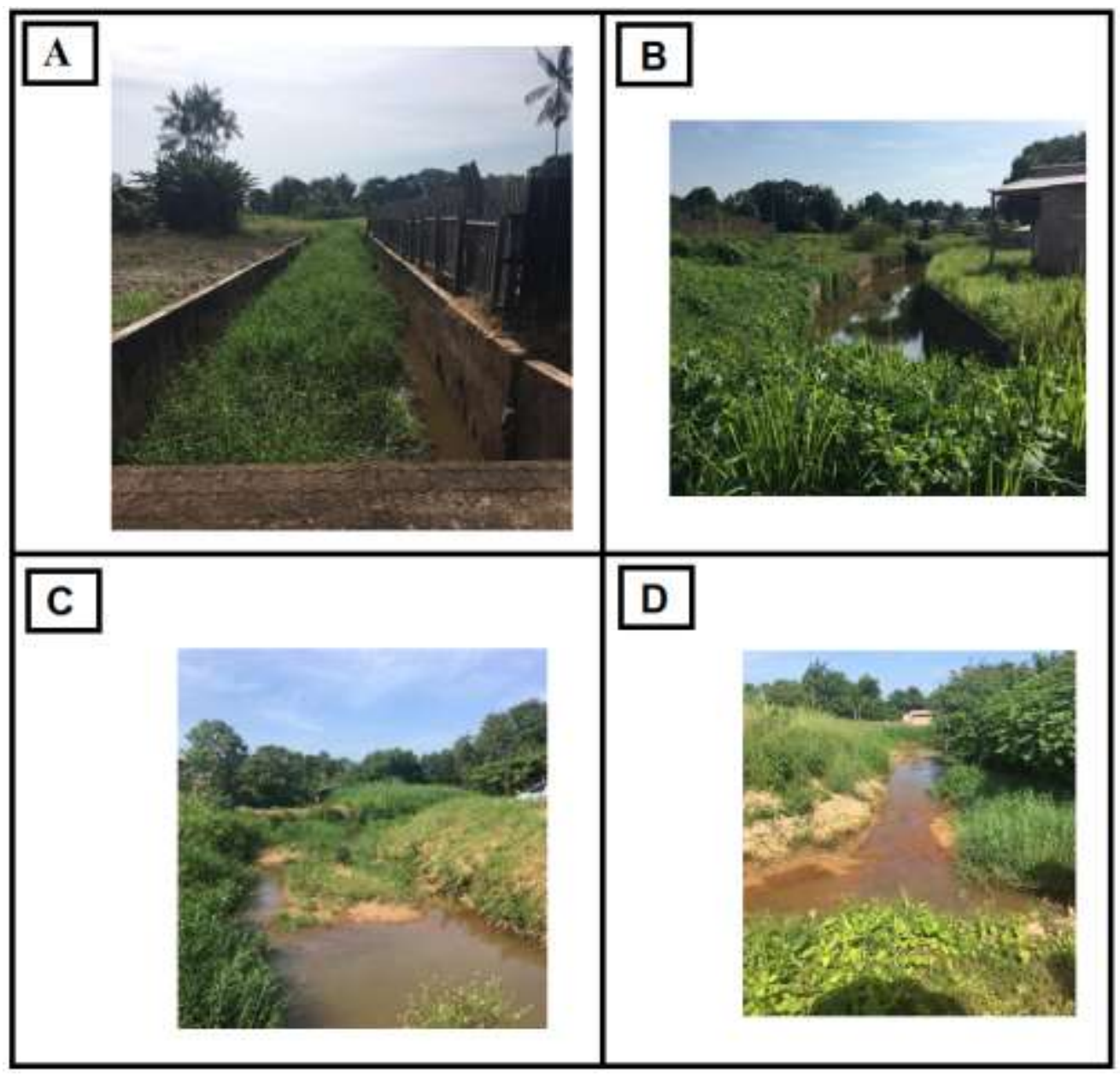

Fonte: Autores

As ações possíveis para essas situações foram: i) Plantio em área total (mudas ou semeadura) e ii) Nucleação (técnicas nucleadoras). De forma complementar, ao ser realizado o plantio de espécies nativas, devem ser retiradas as gramíneas exóticas para evitar competição. Além disso, deve ser ressaltado que na situação 1, as gramíneas devem ser retiradas ao longo do curso do Igarapé no canal.

Para as situações 3 e 4, os níveis percorridos foram:

- 1b: Sem remanescente florestal

- 2a: Em área abandonada

- 3a: Em solo não degradado

- 4b: Inundado ou naturalmente mal drenado.

As ações possíveis para essas situações foram: i) Adensamento e enriquecimento florístico com diversidade genética, ii) plantio em área total (mudas ou semeadura) e iii) manejo de espécies-problema (invasoras ou superabundantes).

Após os cuidados iniciais e escolha das técnicas de restauração deve ser estabelecido quais indicadores serão analisados, bem como, o cronograma de monitoramento da fase de implantação do projeto (12 primeiros meses). Em caso de 
plantio de mudas, por exemplo, pode ser monitorada mensalmente a sobrevivência e desenvolvimento dos indivíduos; em caso de técnicas nucleadoras que não utilizam plantio de mudas, podem ser monitorados os indivíduos regenerantes que estão surgindo na área, por exemplo. Em caso de adensamento e enriquecimento florístico, pode ser utilizada a técnica de linhas de preenchimento associada a linhas de diversidade. Vale ressaltar que essas indicações podem variar e serem substituídas de acordo com o objetivo do projeto a ser implantado. Várias técnicas e métodos de avaliação foram abordados no trabalho e o cronograma deve ser executado de acordo com a disponibilidade técnica e financeira.

\section{Considerações Finais}

A partir da elaboração do referencial teórico foi possível concluir que é essencial a preservação das matas ciliares na Bacia Hidrográfica Amazônica para a conservação da qualidade e disponibilidade de água, bem como, para a manutenção da vida e da biodiversidade local. Uma vez degradada, essas áreas devem ser restauradas a fim de se manter a integridade do local.

Também foi possível concluir que várias técnicas de restauração auxiliam no retorno da área degradada à condição mais próxima do original, e os indicadores ecológicos auxiliam na verificação da viabilidade das diversas técnicas que podem ser aplicadas. Vale ressaltar que a maioria das técnicas de restauração e indicadores encontrados na literatura é voltada para o ambiente rural, no entanto, podem e devem ser adaptados para o contexto urbano.

Ao caracterizar o Igarapé Chico Reis foi possível concluir que seu curso d’agua, bem como trechos de suas matas ciliares, se encontra em processo de degradação. Devido sua localização, bem como importância social e ambiental, esses trechos devem ser recuperados a partir de diferentes técnicas e indicadores. Além disso, deve ser salientado que essa problemática vai além da condição ambiental, tornando uma questão de saúde pública, devido às inúmeras consequências que a ausência de matas ciliares associada à falta de saneamento básico pode gerar para o município de Rorainópolis e, consequentemente, para a Bacia Amazônica. Para trabalhos futuros, os autores indicam que novas técnicas e indicadores de restauração sejam discutidos para a recuperação do Igarapé Chico Reis. Além disso, novos trabalhos devem discutir métodos e cronogramas de execução.

\section{Referências}

Agencia Nacional de Águas - ANA. (2020). Unidade 1: A Bacia Hidrográfica. ANA.

Aquino, F. G.; Albuquerque, L. B.; Alonso, A. M.; Lima, J. E. F. W. \& Sousa, E. S. (2012). Cerrado: restauração de matas de galeria e ciliares. Embrapa Cerrados.

Anderson, M. L. (1953). Plantación en grupos espaciados. Unasylva, 7(s/n.), 61-70.

Attanasio, C. M.; Gandolfi, S.; Zakia, M. J. B.; Veniziani Júnior, J. C. T. \& Lima, W.P. (2012). A importância das áreas riparias para o sustentabilidade hidrológica do uso da terra em microbacias hidrográficas. Bragantia, 71(4), 1-9.

Barni, P.; Arnold, C.; Silva, A. S.; Costa, S. A.; Chagas, F.; Silva, U. S.; Silva, V. A.; Negreiros, R. C.; Souza, E. H.; Silva, F. L.; Muniz, K. C.; Oliveira, P. A.; Pacheco, A.; Barros, E.; Souza, F.; Abreu, F.; Silva, A.; Veloso, J.; Bastos, S.; Kaic, W.; Morais, J. F.; Santos, E. H.; Silva, C. C. \& Lima, R. A. (2015) Avaliação socioambiental na cidade de Rorainópolis, região sul de Roraima. Boletim do Museu Integrado de Roraima 9(2), 23-33.

Brasil. (2012). Dispõe sobre a proteção da vegetação nativa. http://www.planalto.gov.br/ccivil_03/_ato2011-2014/2012/lei/112651.htm

Brasil. (1989). Dispõe sobre a regulamentação do Artigo $2^{\circ}$, inciso VIII, da Lei $n^{\circ} 6.938$, de 31 de agosto de 1981 , e dá outras providências. http://www.planalto.gov.br/ccivil_03/decreto/1980-1989/d97632.htm

Carvalho, A. P. V.; Brumatti, D. V. \& Dias, H. C. T. (2012). Importância do manejo da Bacia Hidrográfica e da determinação e processos hidrológicos. Revista Brasileira de Agropecuária Sustentável (RBAS), 2(2), 148-156.

Castro, D.; Mello, R. S. P. \& Poester, G. C. (2012). Práticas para restauração da mata ciliar. Coletivo de Comunicação.

Castro, S. L. I.; May, L. R. \& Garcias, C. M. (2018). Meio Ambiente e Cidades - Áreas de Preservação Permanente (Apps) marginais urbanas na Lei Federal n.12.651/12. Ciência Florestal, 28(3), 1340-1349. 
Conegundes, P. S. (2018). Caracterização de técnicas para conservação e recuperação de nascentes - estudo de caso: Nascente Parque Ecológico Planalto projeto valoração das nascentes urbanas subcomitês das Bacias Hidrográficas dos Ribeirões Arrudas e Onça. Monografia (Especialização em Gerenciamento de Recursos Hídricos). Universidade Federal de Minas Gerais, Departamento de Ciências Biológicas, Belo Horizonte, MG.

Plano Territorial de Desenvolvimento Rural Sustentável - PTDRS (2010). Propostas de políticas públicas para o território sul de Roraima. Secretaria de Desenvolvimento Territorial.

Costa Filho, P. L. D. R. (2016). Plano de Recuperação da Área de Preservação Permanente (APP) da nascente do córrego Pipa no município de Aparecida de Goiânia, Goiás. Trabalho de Conclusão de Curso (Especialização em Elaboração e gerenciamento de projetos para a gestão municipal de recursos hídricos). Instituto Federal de Educação, Ciência e Tecnologia do Ceará, Campus Fortaleza, Fortaleza, CE.

Corrêa, J. M.; Gerhard, P. \& Figueiredo, R. O. (2012). Ictiofauna de igarapés de pequenas bacias de drenagem em área agrícola do Nordeste Paraense, Amazônia Oriental. Revista Ambiente Água, 7(2), 214-230.

Coutinho, E. C.; Rocha, E. J. P.; Lima, A. M. M. \& Ribeiro, H. M. C. (2019). Variabilidade do regime hidrológico da Bacia Amazônica. Boletim de Geografia, $37(2), 129-147$.

Dalpizzol, J.; Vicente, D. L. S.; Demétrico, L.; Goulart, M. M.; Aquino, M. G. C.; Focking, G. \& Kanieski, M. R. (2021). Avaliação de técnicas nucleadoras em uma Área de Preservação Permanente no Planalto Serrano. Biodiversidade, 20(2), 161-180.

Dornelas, K. C.; Schneider, R. M.; Amaral, A. G.; Ton, A. P. S. \& Mascarenhas, N. M. H. (2021). A biodigestão como ferramenta para a sustentabilidade avícola - uma revisão. Research, Society and Development, 10(12), 1-15.

Embrapa. (2021). Contando Ciência na Web. https://www.embrapa.br/contando-ciencia/bioma-amazonia

Fernandes, M. L. O. \& Andrade, D. B. (2017). Análise do Plano de Recuperação do Igarapé Patauateua (Projeto Reviva Patauateua). Revista eletrônica EcoDebate, 2.866(s/n.), 1-15.

Figueiredo, R. O.; Cak, A. \& Markewitz, D. (2020). Agricultural impacts on hydrobiogeochemical cycling in the amazon: is there any solution? Water, 12(3), $1-14$.

Gonçalves, R. M. G.; Giannotti, E.; Giannotti, J. D. G. \& Silva, A. (2005). Aplicação de modelo de revegetação em áreas degradadas, visando à restauração ecológica da microbacia do córrego da fazenda Itaqui, no Município de Santa Gertrudes, SP. Revista do Instituto Florestal, 17(1), 73-95.

Instituto Brasileiro de Geografia e Estatística - $\quad$ IBGE. $\quad$ (2021). Estimativa da População, 2021. https://ftp.ibge.gov.br/Estimativas_de_Populacao/Estimativas_2021/estimativa_dou_2021.pdf

Instituto Brasileiro de Geografia e Estatística - IBGE. (2017). Rorainópolis. https://cidades.ibge.gov.br/brasil/rr/rorainopolis/historico.

Kuntschik, D. P.; Eduarte, M. \& Uehara, T. H. K. (2014). Matas Ciliares. Secretaria do Meio Ambiente - SMA de São Paulo.

Kutzmy, A. M.; Antoneli, V. \& Maganhotto, R. F. (2019). Características da Mata Ciliar em diferentes usos da terra e os conflitos de usos em Faxinal. Boletim de Geografia, 37(1), 32-49.

Lima, P. A. F. (2014). Eficiência de indicadores da restauração ecológica em Mata Ripária (fase de implantação) no Cerrado, Gama - DF. Dissertação (Mestrado em Ciências Florestais). Universidade de Brasília, Departamento de Engenharia Florestal, Brasília, DF.

Lima, P. A. F.; Gatto, A.; Albuquerque, L. B.; Malaquias, J. V. \& Aquino, F. G. (2016). Crescimento de mudas de espécies nativas na restauração ecológica de matas ripárias. Neotropical Biology and Conservation, 11(2), 72-79.

Lima, P. A. F.; Pachêco, B. S.; Sousa, S. R.; Gatto, A.; Aquino, F. G. \& Albuquerque, L. B. (2015). Indicadores ecológicos: ferramentas para o monitoramento do processo de restauração ecológica. Embrapa Cerrados.

Lima, R. T. S.; T. G.; Martins Júnior, P. J. A.; Portela, C. S.; Santos Júnior, J. D. O. \& Schweickardt, J. C. (2021). Saúde em vista: uma análise da Atenção Primária à Saúde em áreas ribeirinhas e rurais amazônicas. Ciência \& Saúde Coletiva, 26(6), 2053-2064.

Marcuzzo, F. F. N. (2017). Mapa das Bacias $\quad$ N Basil. https://www.researchgate.net/profile/FranciscoMarcuzzo/publication/291116249_Mapa_das_Bacias_e_Sub-Bacias_do_Brasil_-

_MAP_OF_BASINS_AND_SUB-BASIN_HYDROGRAPHIC_OF_BRAZIL_Mapa_de_las_cuencas_y_subcuencas_de_Brasil_-

_baxipendehecipendededetu_-_Carte_des_bassins_et_sousbassins_/links/5845a5bc08ae61f75dd7c9a9/Mapa-das-Bacias-e-Sub-Bacias-do-Brasil-MAP-OF-

BASINS-AND-SUB-BASIN-HYDROGRAPHIC-OF-BRAZIL-Mapa-de-las-cuencas-y-subcuencas-de-Brasil-baxipendehecipendededetu-Carte-des-bassins-

et-sous-bassins.pdf

Marques, A. L. \& Oaigen, E. R. (2006). A Poluição do Igarapé do Chico Reis e suas consequências para a saúde pública. In: V Encontro Nacional de Pesquisa em Educação em Ciências, 5, 2006. Bauru. Anais... Bauru: ABRAPEC.

Martins, S. V. (2012) Restauração Ecológica de Ecossistemas Degradados. Editora UFV.

Medeiros, J. M. M.; Uliana, B. B. \& Araújo, D. S. (2020). Áreas de Preservação Permanente urbanas e parques lineares na Região Norte: conflitos na Lagoa dos Índios, Macapá - Amapá. Revista de Pesquisa em Arquitetura e Urbanismo, 18(s/n.), 1-19.

Molinari, D. C.; Pinto, S. F. L. \& Albuquerque, R. A. (2011). Breves considerações sobre os problemas socioambientais na BR-174: Rorainópolis, Caracaraí, Iracema, Mucajaí e Boa Vista (Estado de Roraima). ACTA Geográfica, s/v.(s/n.), 81-93.

Moura, R. G.; Correia, F. W. S.; Veiga, J. A. P.; Capistrano, V. B. \& Kubota, P. Y. (2021). Avaliação do Brazilian Global Atmospheric Model na simulação dos componentes do balanço de água na Bacia Amazônica. Revista Brasileira de Meteorologia, 36(1), 23-37. 
Oliveira, J. C. C.; Moniz, A. M. H.; Oliveira, A. C. \& Bethonico, M. B. M. (2012). Parâmetros indicadores da qualidade da água no município de Rorainópolis - RR. Ambiente: Gestão e Desenvolvimento, 4(1), 107-117.

Oliveira, T. J. F. (2018). Modelos para recuperação da Floresta Atlântica Estacional Semidecidual na faixa ciliar do rio Paraíba do Sul. Tese (Doutorado em Agronomia). Universidade de Brasília, Centro de Ciências e Tecnologias Agropecuárias, Brasília, DF.

Paranhos, F. R. S. (2012). Proposta de recuperação e manejo de nascente em área rural do município de Álvares Machado - SP. Trabalho de Conclusão de Curso (Engenharia Ambiental). Universidade Estadual Paulista, Faculdade de Ciências e Tecnologia, Presidente Prudente, SP.

Paumgartten, A. E. A. (2018). Restauração ecológica de mata ciliar dominada por pastagem no Nordeste do Pará, Brasil. Dissertação (Mestrado em Ciências Florestais). Universidade Federal Rural da Amazônia, Belém, PA.

Pereira, B. W. F.; Maciel, M. N. M.; Oliveira, F. A.; Alvez, M. A. M. S.; Ribeiro, A. M.; Ferreira, B. M. \& Ribeiro, E. G. P. (2016). Uso da terra e degradação na qualidade da água na bacia hidrográfica do rio Peixe-Boi, PA, Brasil. Ambiente \& Água - An Interdisciplinary Journal of Applied Science, 11(2), $472-485$.

Porto, L. L. M. A.; Motta, E. J. O. \& Souza, C. C. (2019). Plano Nascente Itapecuru: plano de preservação e recuperação de nascentes da bacia hidrográfica do rio Itapecuru. CODEVASF - Companhia de Desenvolvimento dos Vales do São Francisco e do Parnaíba.

Prach, K.; Durigan, G.; Fennessy, S.; Overbeck, G. E.; Torezan, J. M. \& Murphy, S. (2019). A primer on choosing goals and indicators to evaluate ecological restoration success. Restoration Ecology, 27(5), 917-923.

Reis, A. \& Rogalski, J. M. (2006). Novos aspectos na restauração de áreas degradadas. Universidade Federal de Santa Catarina.

Rezende, G. M. (2016). Restauração florestal no sul da Amazônia: métodos para romper barreiras à regeneração natural. Dissertação (Mestrado em Ecologia). Universidade de Brasília, Departamento de Ecologia, Brasília- DF.

Ribeiro, M. F. (2012). Mata Ciliar: Com Ênfase em Hidrologia e Qualidade da Água. Monografia (Especialização em Gerenciamento de Recursos Hídricos e Planejamento Ambiental em Bacias Hidrográficas). Universidade Estadual Paulista, Campus Experimental de Ourinhos, Ourinhos, SP.

Rigueira, D. M. G. \& Mariano-Neto, E. (2013). Monitoramento: uma proposta integrada para avaliação do sucesso em projetos de restauração ecológica em áreas florestais brasileiras. Revista CAITITU, 1(1), 73-88.

Rocha, V. M.; Correia, F. W. S.; Silva, P. R. T. Gomes, W. B. Vergasta, L. A. Moura, R. G.; Trindade, M. S. P. Pedrosa, L. A. \& Silva, J. J. S. (2017). Reciclagem de precipitação na Bacia Amazônica: O papel do transporte de umidade e da evapotranspiração da superfície. Revista Brasileira de Meteorologia, $32(3), 387-398$

Rodrigues, R. R. (2009). Pacto pela restauração de Mata Atlântica: Referencial dos conceitos e ações de restauração florestal. Instituto BioAtlântica.

Rodrigues, R. R. \& Leitão Filho, H. R. (2001). Matas ciliares: conservação e recuperação. Edusp.

Roraima. (2019). Governo do Estado de Roraima: Geografia. http://www.portal.rr.gov.br/index.php?option=com_content\&view=article\&id=33:empresas-eprofissionais-de-comunicacao\&catid $=25$

Rorainópolis. (2021). Prefeitura Municipal de Rorainópolis: História de Rorainópolis. http://rorainopolis.rr.gov.br/pagina/2_Historia-de-Rorainopolis-.html

Sánchez, L. E. (2020). Avaliação de impacto ambiental: conceitos e métodos. Companhia de Letras.

Santos, K. A. (2018). Proposta de Recuperação dos solos expostos dentro da Área de Proteção Ambiental da várzea do Rio Tietê, nos municípios de São Paulo e Guarulhos - SP. Trabalho de Conclusão de Curso (Especialização em Elaboração e gerenciamento de projetos para a gestão municipal de recursos hídricos). Instituto Federal de Educação, Ciência e Tecnologia do Ceará, Campus Fortaleza, Fortaleza, CE.

Secretaria do Meio Ambiente - SMA/SP. (2008). Fixa a orientação para o reflorestamento heterogêneo de áreas degradadas e dá providências correlatas. https://www.infraestruturameioambiente.sp.gov.br/institutodebotanica/wp-content/uploads/sites/235/2014/02/cerad_chave_tomada_decisao_RAD.pdf

Senhoras, E. M. \& Nascimento, F. L. (2020). Rorainópolis: fragmentos geográficos da realidade local. Editora UFRR.

Silva, J. P. (2018). Recuperação da Área de Preservação Permanente de nascentes, no bairro jardim américa, Paraíso do Tocantins. Trabalho de Conclusão de Curso (Especialização em Elaboração e gerenciamento de projetos para a gestão municipal de recursos hídricos). Instituto Federal de Educação, Ciência e Tecnologia do Ceará, Campus Fortaleza, Fortaleza, CE.

Silva, M. S. R. (2013). Bacia Hidrográfica do Rio Amazonas: contribuição para o enquadramento e preservação. Tese (Doutorado em Química). Universidade Federal do Amazonas, Departamento de Química, Manaus, AM.

Siqueira, L. P. \& Mesquita, C. A. B. (2007). Meu pé de Mata Atlântica: experiências de recomposição florestal em propriedades particulares no Corredor Central. Instituto BioAtlântica.

Society for Ecological Restoration - SER. (2004). SER International primer on ecological restoration. Society for Ecological Restoration International.

Souza, A. S. \& Barni, P. E. (2018). Análise espacial da Área de Preservação Permanente (APP) do igarapé Chico Reis, sede municipal de Rorainópolis - RR. In: XIII Semana Nacional de Ciência e Tecnologia no Estado de Roraima, 13, 2018. Boa Vista. Anais... Boa Vista: SNCT.

Tavares, S, R. L. Curso de recuperação de áreas degradadas: a visão da Ciência do Solo no contexto do diagnóstico, manejo, indicadores de monitoramento e estratégias de recuperação. Embrapa Solos.

Três, D. R. \& Reis, A. (2009). Técnicas nucleadoras na restauração de floresta ribeirinha em área de Floresta Ombrófila Mista, Sul do Brasil. Biotemas, 22(4), 59-71. 
Research, Society and Development, v. 10, n. 15, e341101522816, 2021

(CC BY 4.0) | ISSN 2525-3409 | DOI: http://dx.doi.org/10.33448/rsd-v10i15.22816

Validacar. (2019). Análise e validação do CAR no estado do Roraima. Projeto ValidaCAR.

Veras, A. T. R.; Anjos, J. N. S.; Santos, A. F. P.; Paixão, S. U. A. \& Oliveira, R. V. (2012). Dinâmica socioespacial da cidade de Rorainópolis-RR. In: XV Encontro da Associação Nacional de Pós-Graduação e Pesquisa em Planejamento Urbano e Regional, 15, 2012. Recife. Anais.... Recife: ENANPUR.

Wittmann, F. \& Junk, W. J. (2016). Amazon River Basin. In: Finlayson, C.; Milton, G.; Prentice, R.; Davidson, N. (Eds.). The Wetland Book. Springer. 